\title{
Comparison of attendance and emergency admission patterns at accident and emergency departments in and out of London
}

\author{
Raymond F Jankowski, Sundhiya Mandalia
}

Abstract
Objective-To compare the sociodemographic characteristics, diagnoses, and mode of referral of people and emergency admissions between an accident and emergency department in inner London and one in a town outside London.

Design-Standardised questionnaire completed prospectively over two weeks by fieldworkers in each accident and emergency department.

Setting-Accident and emergency departments in an inner London teaching hospital and an associated teaching hospital outside London.

Subjects-3039 adults newly attending the departments, 1476 in inner London and 1563 outside London.

Main outcome measures-Sociodemographic characteristics, diagnosis, mode of referral, and whether the patient was admitted.

Results-General practitioner referrals accounted for similar proportions of the adult attendances $(12 \%$ in inner London, 15\% outside London). People attending at the inner London department were more likely to be tourists or long distance commuters $(12 \%(179 / 1476) v 6 \%(95 / 1563))$, single $(43 \%(643) v$ $32 \%(505))$, to live alone $(24 \%(360) v 14 \%(225))$, to have moved recently $(13 \%(194) v 7 \%(107))$, or to be homeless $(3 \cdot 3 \%(48) v 0 \cdot 6 \%(10))$. Broad clinical groupings of patients were similar in both departments. 291 people were admitted in inner London and 284 outside London. The proportions admitted from each sociodemographic group were similar in the two hospitals.

Conclusion-Differences in sociodemographic characteristics were more important than general practice referral patterns in determining the differences in people attending at accident and emergency departments inside and outside London: Many of these characteristics are likely to be found in other inner city populations. A strategy to improve acute care in inner London should take account of the needs of these sociodemographically different groups.

Division of Community Health, United Medical and Dental School, St Thomas's Campus, London SE1 7EH Raymond F Jankowski, lecturer in public health medicine

Sundhiya Mandalia, statistician

Correspondence to: Dr Jankowski.

BMF 1993;306:1241-3 mergency departments rising throughout the United Kingdom, particularly in urban areas. ${ }^{3}$ Inner London departments are believed to have extra problems because a larger proportion of their workload comes from commuters, tourists, and a highly mobile population compared with departments outside of London..$^{46}$ Patients with minor problems are thought to present more often to inner London departments because of poor access to good quality primary care. ${ }^{6}$ Current routine data to confirm these perceptions of inner London accident and emergency departments are largely unavailable.

We compared the sociodemographic characteristics, diagnoses, and mode of referral of people attending and admitted through two accident and emergency departments; one in inner London and the other in a town about $50 \mathrm{~km}$ ( 30 miles) outside London. The aim was to determine whether there are unique problems in inner London.

\section{Methods}

The two accident and emergency departments were chosen because they report similar annual numbers of new attendances (62000 to 63000). Average annual attendances at accident and emergency departments in England range from 35000 to 65000 a year. ${ }^{3}$ Both hospitals had similar policies with respect to patient attendance; emergency admissions through the accident and emergency department accounted for $88 \%$ of all emergency admissions in the inner London hospital and $90 \%$ in the provincial hospital.

Data were collected on adults newly attending each accident and emergency department. The London department was studied over the first two weeks in December and the department outside London during the last two weeks in January. Children under 16 years, psychiatric patients, and private patients were excluded as they did not compete for the same bed pool.

Data in both departments were collected by the same 10 trained fieldworkers, organised in shifts, using a standardised questionnaire and protocol. The data were obtained by interviewing both doctors and patients. If a patient was unconscious or confused data were sought from relatives or companions. The details recorded included sociodemographic characteristics, reason for attendance, diagnosis, investigations, and treatment. Diagnoses were then coded according to the international classification of primary care. ${ }^{7}$

For the purposes of analysis, long distance commuters were defined as those who regularly travelled to work in the area of the hospital but whose permanent residence was outside the London postal area (for the inner London department) or outside the catchment area (for the department outside London). A tourist was defined as a person visiting the area on vacation whose permanent address was outside these same areas.

General practice referrals were classified as formal (where contact was made by letter or telephone to the accident and emergency staff) or informal. Informal referrals were defined as those in which the patients 
were advised to attend the accident and emergency department by their general practitioner or practice staff without the practice contacting the accident and emergency department. Confidence intervals were calculated with confidence interval analysis program.

\section{Results}

Complete data were collected for 3039 people attending the two departments. Of 1565 people eligible in inner London and 1585 outside London, 1.476 (94\%) and $1563(99 \%)$ had questionnaires completed. The pattern of attendances by day of the week and time of day was similar in the two hospitals. Data were obtained on 291 of 292 people admitted as emergencies in inner London and all 284 admitted outside London.

\section{ATTENDANCE}

Table I summarises the characteristics of adults attending the two departments. Although the proportion of elderly patients was similar in the two hospitals, other sociodemographic characteristics differed. Most people were self referred and referrals from other sources accounted for a similar proportion in the two departments studied (table II).

Most people had come directly to the accident and emergency doctors without consulting their general practitioner: $89 \%(1317 / 1476)$ in inner London and $88 \%(1384 / 1563)$ outside London. The remainder had mainly presented after direct general practitioner

TABLE I-Summary of characteristics of adults attending accident and emergency departments

\begin{tabular}{|c|c|c|c|c|}
\hline & \multicolumn{2}{|c|}{ Inner London $(n=1476)$} & \multicolumn{2}{|c|}{ Outside London $(n=1563)$} \\
\hline & No (\%) & $\begin{array}{l}95 \% \text { Confidence } \\
\text { interval for } \\
\text { percentage }\end{array}$ & No (\%) & $\begin{array}{l}95 \% \text { Confidence } \\
\text { interval for } \\
\text { percentage }\end{array}$ \\
\hline $\begin{array}{l}\text { Over } 65 \text { years old } \\
\text { Lives alone } \\
\text { Single } \\
\text { Moved in past three months } \\
\text { Homeless } \\
\text { Commuter or tourist }\end{array}$ & $\begin{array}{c}269(18 \cdot 2) \\
360(24 \cdot 4) \\
634(43 \cdot 0) \\
194(13 \cdot 1) \\
48(3 \cdot 3) \\
179(12 \cdot 1)\end{array}$ & $\begin{array}{c}16 \cdot 3 \text { to } 20 \cdot 2 \\
22 \cdot 2 \text { to } 26 \cdot 6 \\
40 \cdot 4 \text { to } 45 \cdot 5 \\
11 \cdot 4 \text { to } 14 \cdot 9 \\
2 \cdot 4 \text { to } 4 \cdot 3 \\
10 \cdot 5 \text { to } 13 \cdot 8\end{array}$ & $\begin{array}{l}279(17 \cdot 9) \\
225(14 \cdot 4) \\
505(32 \cdot 3) \\
107(6 \cdot 8) \\
10(0 \cdot 6) \\
95(6 \cdot 1)\end{array}$ & $\begin{array}{c}16.0 \text { to } 19 \cdot 7 \\
12 \cdot 7 \text { to } 16 \cdot 1 \\
30.0 \text { to } 34.6 \\
5.6 \text { to } 8 \cdot 2 \\
0.3 \text { to } 1.2 \\
5.0 \text { to } 7 \cdot 4\end{array}$ \\
\hline
\end{tabular}

TABLE II-Mode of referral to accident and emergency

\begin{tabular}{|c|c|c|c|c|}
\hline & \multicolumn{2}{|c|}{ Inner London $(n=1476)$} & \multicolumn{2}{|c|}{ Outside London $(n=1563)$} \\
\hline & No (\%) & $\begin{array}{l}95 \% \text { Confidence } \\
\text { interval for } \\
\text { percentage }\end{array}$ & No (\%) & $\begin{array}{l}95 \% \text { Confidence } \\
\text { interval for } \\
\text { percentage }\end{array}$ \\
\hline Self & $984(66 \cdot 7)$ & $64 \cdot 3$ to $69 \cdot 1$ & $1058(67 \cdot 7)$ & $65 \cdot 4$ to $70 \cdot 0$ \\
\hline Own general practitioner & $183(12 \cdot 4)$ & $10 \cdot 7$ to $14 \cdot 1$ & $229(14 \cdot 7)$ & 12.9 to 16.4 \\
\hline Deputising doctor & $14(0.9)$ & 0.5 to 1.6 & $19(1 \cdot 2)$ & 0.7 to 1.9 \\
\hline Informal referral from general practice & $28(1.9)$ & 1.3 to 2.7 & $42(2 \cdot 7)$ & 2.0 to $3 \cdot 6$ \\
\hline Office, shop, workplace & $64(4 \cdot 3)$ & 3.4 to 5.5 & $75(4 \cdot 8)$ & 3.8 to 6.0 \\
\hline Private general practitioner or clinic & $5(0 \cdot 3)$ & 0.1 to 0.8 & $18(1 \cdot 2)$ & 0.7 to 1.8 \\
\hline Nursing home & $20(1 \cdot 4)$ & $0 \cdot 8$ to $2 \cdot 1$ & $14(0.9)$ & 0.5 to 1.5 \\
\hline Police & $18(1 \cdot 2)$ & 0.7 to 1.9 & $18(1 \cdot 2)$ & 0.7 to 1.8 \\
\hline Other & $69(4 \cdot 7)$ & 3.7 to 5.9 & $63(4 \cdot 0)$ & $3 \cdot 1$ to $5 \cdot 1$ \\
\hline Not known & $91(6 \cdot 2)$ & 5.0 to 7.5 & $27(1 \cdot 7)$ & 1.1 to 2.5 \\
\hline
\end{tabular}

TABLE III-Diagnostic categories of patients seen by accident and emergency doctor

\begin{tabular}{|c|c|c|c|c|}
\hline \multirow[b]{2}{*}{ Diagnostic categories } & \multicolumn{2}{|c|}{ Inner London $(n=1317)$} & \multicolumn{2}{|c|}{ Outside London $(n=1384)$} \\
\hline & No (\%) & $\begin{array}{l}95 \% \text { Confidence } \\
\text { interval for } \\
\text { percentage }\end{array}$ & No $(\%)$ & $\begin{array}{l}95 \% \text { Confidence } \\
\text { interval for } \\
\text { percentage }\end{array}$ \\
\hline Circulatory & $62(4 \cdot 7)$ & 3.6 to 6.0 & $62(4 \cdot 5)$ & 3.4 to 5.7 \\
\hline Gastrointestinal & $104(8)$ & 6.5 to 9.5 & $63(4 \cdot 6)$ & 3.5 to 5.8 \\
\hline Respiratory & $86(6.5)$ & $5 \cdot 3$ to 8.0 & $65(4 \cdot 7)$ & 3.6 to 6.0 \\
\hline Musculoskeletal & $316(24)$ & $21 \cdot 7$ to $26 \cdot 3$ & $457(33)$ & 30.5 to 35.5 \\
\hline General (non-specific) & $86(6.5)$ & $5 \cdot 3$ to 8.0 & $68(4 \cdot 9)$ & 3.8 to 6.2 \\
\hline Skin (including minor trauma) & $358(27 \cdot 2)$ & 24.8 to $29 \cdot 8$ & $437(31 \cdot 6)$ & $29 \cdot 1$ to $34 \cdot 0$ \\
\hline Urological & $46(3.5)$ & $2 \cdot 6$ to 4.6 & $26(1.9)$ & 1.2 to $2 \cdot 7$ \\
\hline Gynaecological & $65(4 \cdot 9)$ & 3.8 to 6.2 & $19(1 \cdot 4)$ & 0.8 to 2.1 \\
\hline Neurological & $55(4 \cdot 2)$ & 3.2 to $6 \cdot 2$ & $54(3.9)$ & $3 \cdot 0$ to $5 \cdot 1$ \\
\hline Blood disorders & $9(0.7)$ & 0.3 to 1.3 & $2(0 \cdot 1)$ & 0.01 to 0.5 \\
\hline Psychological & $37(2 \cdot 8)$ & 2.0 to 3.8 & $11(0 \cdot 8)$ & 0.4 to 1.4 \\
\hline Endocrine or metabolic & $9(0.7)$ & 0.3 to 1.3 & $11(0 \cdot 8)$ & 0.4 to 1.4 \\
\hline Other & $35(2 \cdot 7)$ & 1.9 to 3.7 & $63(4 \cdot 6)$ & 3.5 to 5.8 \\
\hline Uncertain of diagnosis & $22(1 \cdot 7)$ & 1.1 to $2 \cdot 5$ & $20(1 \cdot 4)$ & 0.8 to $2 \cdot 2$ \\
\hline Unknown & $27(2 \cdot 1)$ & 1.4 to 3.0 & $26(1.9)$ & $1 \cdot 2$ to $2 \cdot 7$ \\
\hline
\end{tabular}

referral to specialty teams. The proportions in each broad diagnostic categories were similar in both hospitals (table III). Few patients presented to the department outside London with gynaecological or psychological disorders as these patients were referred elsewhere.

\section{EMERGENCY ADMISSIONS}

Among patients requiring emergency admission the broad diagnostic categories were similar in both departments with the exception of circulatory, gynaecological, psychological, and urological disorders (table IV).

The demographic characteristics of people requiring emergency admissions to the two departments differed less significantly than for attendances (table V). Emergency admission rates were similar in both departments; $19 \cdot 7 \% \quad(291 / 1476 ; 95 \%$ confidence interval $17 \cdot 7 \%$ to $21 \cdot 7 \%$ ) in inner London and $18.2 \%$ $(284 / 1563 ; 16.3 \%$ to $20 \cdot 1 \%)$ outside London. The emergency admissions rate was $42 \%(113 / 269 ; 36 \%$ to $48 \%$ ) outside London for patients over 65 years old compared with $51 \%(142 / 279 ; 45 \%$ to $57 \%)$ in inner London. The admission rate for tourists and commuters was $9 \%(17 / 179$ and $9 / 95$ respectively) in both departments $(95 \%$ confidence intervals were $5 \cdot 6 \%$ to $14 \cdot 8 \%$ and $4 \cdot 4 \%$ to $17 \cdot 2 \%$ respectively).

\section{Discussion}

The number of adults attending the two accident and emergency departments, and the pattern of attendance by day of week and time of day were similar in the two hospitals. As in previous studies, the proportion of people aged over 65 years attending was the same in inner London and outside London. ${ }^{\circ}$ Both departments had similar case-mix, as defined by broad diagnostic groups.

There were, however, some important differences between people attending the departments in inner London and outside London. The department in inner London had a higher proportion of single people, people who live alone, those who had recently moved, those who were homeless, and long distance commuters or tourists. ${ }^{6}$ As these groups may not have access to local primary health care, it might be expected that a lower proportion of attenders in inner London would be referred by their general practitioner. ${ }^{46}$ However, unlike in a previous study, ${ }^{6}$ we found that the proportion of attenders referred by their own general practitioner was similar in the inner and outside London departments and represented only a small proportion of the total adult attenders. Most patients were self referred and the proportion referred from other sources, including deputising doctors, was also similar in both departments. The proportion of patients informally referred from practices was also similar in both departments.

Both the Tomlinson and King's Fund reports stated that people attending accident and emergency departments in inner London are more likely to present with minor disorders. ${ }^{12}$ The reports argue that such minor conditions could be dealt with by a good general practitioner in a well organised practice. In this study, however, the proportion of people attending with musculoskeletal or skin complaints, most of which are due to minor trauma, was lower in inner London than outside London. Otherwise the case-mix was similar in both hospitals. Our findings therefore do not support the claims that general practice referral patterns, including deputies, add substantially to the attendances at accident and emergency departments in inner London. The higher rate of attendance at accident and emergency departments, which has previously been observed in inner London, ${ }^{4}$ may reflect sociodemo- 


\begin{tabular}{|c|c|c|c|c|}
\hline \multirow[b]{2}{*}{ Diagnostic categories } & \multicolumn{2}{|c|}{ Inner London $(n=219)$} & \multicolumn{2}{|c|}{ Outside London $(n=284)$} \\
\hline & No (\%) & $\begin{array}{l}95 \% \text { Confidence } \\
\text { interval for } \\
\text { percentage }\end{array}$ & No (\%) & $\begin{array}{l}95 \% \text { Confidence } \\
\text { interval for } \\
\text { percentage }\end{array}$ \\
\hline Circulatory & $56(19)$ & $14 \cdot 7$ to $23 \cdot 8$ & $90(32)$ & $26 \cdot 3$ to $37 \cdot 1$ \\
\hline Gastrointestinal & $52(18)$ & 13.5 to 22.3 & $57(20)$ & $15 \cdot 4$ to $24 \cdot 7$ \\
\hline Respiratory & $37(13)$ & 8.9 to 16.5 & $51(18)$ & 13.5 to 22.4 \\
\hline Musculoskeletal & $20(7)$ & $4 \cdot 2$ to $10 \cdot 4$ & $29(10)$ & 6.7 to 13.7 \\
\hline General (non-specific) & $11(4)$ & 1.9 to 6.7 & $24(8)$ & 5.5 to 12.3 \\
\hline Skin & $12(4)$ & $2 \cdot 1$ to $7 \cdot 1$ & $5(2)$ & 0.6 to 4.1 \\
\hline Urological & $25(9)$ & $5 \cdot 6$ to $12 \cdot 0$ & $6(2)$ & 0.8 to 4.6 \\
\hline Gynaecological & $29(10)$ & $6 \cdot 8$ to 14.0 & $1(0 \cdot 3)$ & 0.0 to 1.9 \\
\hline Neurological & $11(4)$ & 1.9 to 6.7 & $10(4)$ & 1.7 to 6.3 \\
\hline Blood disorders & $11(4)$ & 1.9 to 6.7 & $3(1)$ & 0.2 to $3 \cdot 1$ \\
\hline Psychological & $16(5)$ & 3.2 to 8.8 & 0 & \\
\hline Endocrine or metabolic & $5(2)$ & 0.6 to 4.0 & $5(2)$ & $0 \cdot 6$ to $4 \cdot 1$ \\
\hline Other & $6(2)$ & 0.8 to 4.4 & $3(1)$ & 0.2 to 3.1 \\
\hline
\end{tabular}

TABLE V-Demographic characteristics of patients admitted as an emergency

\begin{tabular}{|c|c|c|c|c|}
\hline & \multicolumn{2}{|c|}{ Inner London $(n=291)$} & \multicolumn{2}{|c|}{ Outside London $(n=284)$} \\
\hline & No (\%) & $\begin{array}{l}95 \% \text { Confidence } \\
\text { interval for } \\
\text { percentage }\end{array}$ & No (\%) & $\begin{array}{l}95 \% \text { Confidence } \\
\text { interval for } \\
\text { percentage }\end{array}$ \\
\hline $\begin{array}{l}\text { Over } 65 \text { years old } \\
\text { Lives alone } \\
\text { Single } \\
\text { Moved in past three months } \\
\text { Commuter or tourist }\end{array}$ & $\begin{array}{l}113(39) \\
81(28) \\
84(29) \\
26(9) \\
17(6)\end{array}$ & $\begin{array}{l}33 \cdot 2 \text { to } 44 \cdot 4 \\
22 \cdot 7 \text { to } 33 \cdot 0 \\
23 \cdot 7 \text { to } 34 \cdot 1 \\
5.9 \text { to } 12 \cdot 8 \\
3 \cdot 4 \text { to } 9 \cdot 2\end{array}$ & $\begin{array}{c}142(50) \\
57(20) \\
45(16) \\
11(4) \\
9(3)\end{array}$ & $\begin{array}{l}44 \cdot 2 \text { to } 55 \cdot 8 \\
15 \cdot 4 \text { to } 24 \cdot 7 \\
11 \cdot 6 \text { to } 20 \cdot 1 \\
2.0 \text { to } 6 \cdot 8 \\
1.5 \text { to } 5 \cdot 9\end{array}$ \\
\hline
\end{tabular}

graphic factors rather than primary care referral patterns.

\section{ADMISSION PATTERNS}

The major demographic factor associated with admission was being over 65 years old. A slightly higher proportion of patients admitted outside London were elderly, and the admission rate among people aged over 65 years was also higher than in inner London. Otherwise the demographic characteristics of the patients admitted in the two hospitals differed in the same way as among all those attending. With the exception of people who were single or living alone, however, these sociodemographic differences did not contribute substantially to the number of admissions. A higher proportion of tourists and commuters have been shown to attend inner London hospitals in the past, ${ }^{\circ}$ and this has been used as an argument for additional resources. We found that the difference in the proportion of tourists and commuters admitted in the two hospitals was smaller than the difference in the proportion of all attenders. This is because commuters and tourists are less likely to be admitted to hospital beds than other attenders and present mainly with minor traumatic injuries.

Overall emergency admissions rates in the two hospitals were similar. In addition, apart from a larger proportion of circulatory disorders in the hospital outside London and smaller numbers of gynaecology cases, the case mix of admissions was similar. The excess in circulatory disorders is in part explained by the greater proportion of patients aged over 65 years. The lack of gynaecological problems reflects the fact that this specialty is not based at the study hospital.

SOURCES OF BIAS

Three potential biases may have occurred in this study. Firstly, because of the different study periods in

each hospital, attendances at the inner London department could have been inflated with Christmas shoppers. However, analysis of the department register showed that attendance was in fact less than expected for that time of year. Secondly, the overall response rate was lower in the inner London department than in that outside London. From examination of both medical records and register data in the departments, non-respondents were similar to respondents with respect to mode of referral, place of residence, and diagnoses. Thirdly, there were more patients at the inner London department where data on mode of referral were not ascertained because of patient's refusal or inability to answer. In these cases, the accident and emergency department had no record of a telephone message or letter received from other agencies. It is therefore unlikely that a substantial proportion of patients referred by general practitioners were misclassified into this group.

In conclusion, our findings show that attendance patterns at the inner London accident and emergency department were similar to those outside London, with respect to overall numbers and diagnostic categories. The study also suggests general practice referral patterns do not account for an increased proportion of the attendances at accident and emergency departments in inner London. There are potentially important sociodemographic differences between attenders inside and outside of London, but these do not cause excess admission rates. The Tomlinson inquiry identified general practice as the major weak link in the acute services. This study identifies influences other than general practice which operate to increase the problems of inner London accident and emergency departments. With the possible exceptions of the tourists, many of these sociodemographic factors may be similar in other inner cities. The real challenge is to devise a strategy to cope with the groups in the population identified in this study which contribute to the burden of accident and emergency departments in London.

We thank the medical and nursing staff of both accident and emergency departments for their enthusiastic cooperation, and the patients, specialist staff, and the fieldworkers. We are grateful to Professor Holland, Dr Charles Wolfe of the department of public health medicine, and David Armstrong, Professor Morrell, Nicky Britten, Fiona Gelder, Judy Green, and Jenny Bartholomew of the department of general practice, United Medical and Dental School, for helpful advice. We thank Dr Mary Ramsay for immense support and advice in the study and preparing the manuscript and the King's Fund for generously funding this study.

1 Tomlinson B. Report of the inquiry into London's health service, medical education and research. London: HMSO, 1992. (Tomlinson report.)

2 King's Fund Commission. $A$ user perspective: views on London's acute health services. London: King's Fund, 1992.

3 National Audit Office. NHS accident and emergency departments in England. London: HMSO, 1992.

4 Inwald AC. A comparison of self-referred patients to accident and emergency departments. I R Coll Gen Pract 1980;30:220.

5 Milner PC, Nicholl JP, Williams BT. Variations in demand for accident and emergency departments in England from 1974 to 1985. I Epidemiol Community Health 1988;42:274-8.

6 Farmer DT, Chambers JD. The relationship between accident and emergency departments and the availability of general practitioner services-a study in six London hospitals. London: Kings Fund, 1982.

7 Lamberts H, Wood M. ICPC international classification of primary care. Oxford: Oxford Medical Publications, 1987.

(Accepted 4 March 1993) 